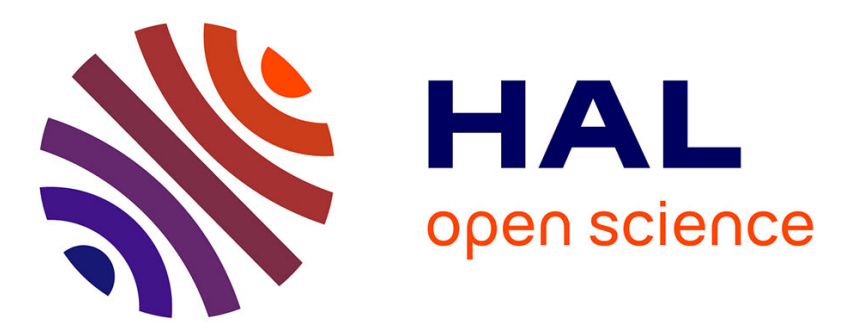

\title{
Assessing tree dendrometrics in young regenerating plantations using terrestrial laser scanning
}

Ying Li, Carsten Hess, Henrik von Wehrden, Werner Härdtle, Goddert von

Oheimb

\section{- To cite this version:}

Ying Li, Carsten Hess, Henrik von Wehrden, Werner Härdtle, Goddert von Oheimb. Assessing tree dendrometrics in young regenerating plantations using terrestrial laser scanning. Annals of Forest Science, 2014, 71 (4), pp.453-462. 10.1007/s13595-014-0358-4 . hal-01102217

\section{HAL Id: hal-01102217 \\ https://hal.science/hal-01102217}

Submitted on 12 Jan 2015

HAL is a multi-disciplinary open access archive for the deposit and dissemination of scientific research documents, whether they are published or not. The documents may come from teaching and research institutions in France or abroad, or from public or private research centers.
L'archive ouverte pluridisciplinaire HAL, est destinée au dépôt et à la diffusion de documents scientifiques de niveau recherche, publiés ou non, émanant des établissements d'enseignement et de recherche français ou étrangers, des laboratoires publics ou privés. 


\title{
Assessing tree dendrometrics in young regenerating plantations using terrestrial laser scanning
}

\author{
Ying Li • Carsten Hess • Henrik von Wehrden • \\ Werner Härdtle • Goddert von Oheimb
}

Received: 12 September 2013 / Accepted: 6 January 2014 /Published online: 29 January 2014

(C) INRA and Springer-Verlag France 2014

\begin{abstract}
- Context Terrestrial laser scanning (TLS) provides a valuable tool for the retrieval of detailed individual-tree structural parameters, but has never previously been applied to young stands under field conditions.

- Aims The aim was to explore the performance of TLS in a young tree plantation located in a heterogeneous environment in subtropical China.

- Methods We investigated 438 young trees for congruence between direct field and TLS measurements of total tree height, stem diameter at ground height, and length and height of the longest branch using correlation tests. We applied generalized linear models to examine whether congruence was affected by the observed structural parameter or extrinsic factors (e.g., potential occlusion, point cloud quality).

- Results TLS made it possible to detect trees higher than $40 \mathrm{~cm}$. The TLS-retrieved data were highly congruent with the
\end{abstract}

\section{Handling Editor: Jean-Michel Leban}

Contribution of the co-authors Ying Li: designed the study, performed the research, analyzed data and wrote the manuscript

Carsten Hess: performed the research, analyzed data and contributed new methods

Henrik von Wehrden: analyzed data and revised the manuscript

Werner Härdtle: revised the manuscript

Goddert von Oheimb: designed the study, supervised the work and coordinated the research project

Y. Li $(\bowtie) \cdot$ C. Hess $\cdot$ H. von Wehrden · W. Härdtle $\cdot$ G. von Oheimb Faculty Sustainability, Institute of Ecology, Leuphana University Lüneburg, Scharnhorststr.1, 21335 Lüneburg, Germany

e-mail: li@leuphana.de

H. von Wehrden

Center for Methods, Leuphana University Lüneburg,

Scharnhorststr.1, 21335 Lüneburg, Germany

H. von Wehrden

Research Institute of Wildlife Ecology, Savoyen Strasse 1,

Vienna 1160, Austria data obtained from direct measurements. The poor descriptions of stems and branches of some individuals of small-sized and leaf-on tree species were due to occlusion by ground vegetation and leaf-on branches. Observed structural parameter and extrinsic factors did not explain the variance between the two approaches.

- Conclusion TLS proved to be a promising tool for highresolution, non-destructive analyses of tree dendrometrics in young regenerating plantations.

Keywords BEF-China $\cdot$ Regeneration phase $\cdot$ Subtropical China $\cdot$ Point cloud $\cdot$ TLS

\section{Introduction}

Competition for light is broadly recognized as a key factor determining plant growth. In trees, these interactions lead primarily to morphological responses of the crown (Grams and Anderson 2007), because crown dimensions and crown architecture strongly determine the individual's ability to intercept light and to shade neighboring trees (Brisson 2001). Although the expression of crown traits in individual trees is constrained by genetic and mechanical properties, individuals may show plastic responses within certain thresholds as a reaction to local neighborhood interactions or, more generally, to local environmental conditions. Crown responses to these conditions are the aggregate effect of the differential spatial development of single branches (Stoll and Schmid 1998; Sumida et al. 2002). Therefore, detailed information on branching patterns and the growth and mortality of single branches of individual trees as well as on local site conditions are needed to explain and model the spatiotemporal development of crowns (Pretzsch et al. 2011). To obtain this information by direct field measurement is, however, challenging and time-consuming, and thus costly (Fleck et al. 2011). In recent 
years, technically intensive high-resolution inventory tools have been used to acquire individual-tree data.

Airborne laser scanning (ALS) techniques have been successfully applied in determining canopy structure (Vehmas et al. 2011) and measuring essential parameters of individual-tree crown characteristics, such as crown base height, crown area and crown volume (Jung et al. 2011). Compared to field measurements, ALS slightly underestimates tree parameters (Zimble et al. 2003). More importantly, ALS is largely restricted to the top canopy layer, whereas the elements in the lower canopy are recorded in less detail due to signal occlusion by upper canopy elements (Hilker et al. 2010; Jung et al. 2011). Furthermore, ALS has some constraints in terms of the fine-scale spatial resolution (in the order of millimeters or a few centimeters) of structural elements (van Leeuwen and Nieuwenhuis 2010).

Terrestrial laser scanning (TLS) has now been established as an alternative approach for measurement of three-dimensional (3D) structural elements of trees (Fleck et al. 2011; Jung et al. 2011; Schilling et al. 2012). TLS is a light detection and ranging (LiDAR) system capable of acquiring 3D structural high-resolution information with a level of detail that is considerably higher than ALS (Lichti et al. 2002). Up to now, TLS has mainly been applied in forest science to analyze standard tree and stand dendrometrics such as stem diameter, tree height, stem position, tree density, basal area and trunk volume (Hopkinson et al. 2004; Dassot et al. 2011). Recently, the use of TLS has been intensified to analyze 3D tree topology, canopy and individual-tree crown structure as well as the wood volume of branches (Bucksch et al. 2010; Dassot et al. 2011, 2012; Schilling et al. 2012). However, as the main interest when conducting forest inventories is in the wood volume of adult trees, TLS applications have focused almost exclusively on adult trees or mature stands. A central task of forest science and forest ecology, however, is the analysis of growth dynamics in the regeneration phase. This phase is often characterized by a high tree density, but also by a mixture of various tree species, and, thus, intensive and complex tree-tree interactions. The processes operating in this early phase of stand development are essential for the future forest structure and composition (Kobe 2006), and hence, it is vital to understand the underlying mechanisms of tree-tree interactions. TLS offers the opportunity to conduct rapid, non-destructive, accurate and extensive measurements of a large number of individual trees over time in order to analyze tree growth dynamics in general, but in particular to investigate the spatial development of crowns in detail (Dassot et al. 2011). To our knowledge, however, the feasibility of TLS to determine growth parameters of young trees under field conditions has never been explored before. We are aware of only one study which applied TLS to investigate juvenile trees, albeit under controlled conditions; this study analyzed 6-year-old beech (Fagus sylvatica) trees planted individually in buckets and kept under a roof in an experimental botanical garden (Seidel et al. 2011a). Several specific challenges are associated with the application of TLS for smaller trees or younger stands: (1) the dimension of the main wood components (i.e., trunk and the first- and secondorder branches) may be too small to be resolved at high quality by the laser scanner; (2) the structural density is higher than in adult trees or mature stands, potentially resulting in a relatively high level of occlusion (Dassot et al. 2011); (3) the ground layer vegetation may occlude a substantial part of the individual trees; (4) adverse impact of mild to moderate wind on scan quality is largely restricted to the smallest tree constituents (Côté et al. 2011), which make up a relatively high proportion of young trees' structure.

The aim of our study is to explore the performance of TLS in a young experimental tree plantation in a heterogeneous environment by comparing TLS-derived tree structural data with those obtained by direct field measurements. We conducted the study in the framework of the BEF-China project (BEF: Biodiversity and Ecosystem Functioning). BEF-China is a new forest BEF experiment that was established in subtropical China from 2009 to 2010 (Yang et al. 2013; Bruelheide et al. 2014). A pool of 40 native tree species was planted on 566 plots and a net area of 38.4 ha. Species richness and composition were experimentally manipulated to study their effects on a range of ecosystem functions, including primary productivity, carbon and nutrient cycling, and soil processes. Conventional inventories are conducted annually to study the effect of local environmental conditions such as size and species identity of neighboring trees or slope inclination on individual-tree growth and crown dynamics. Here, we compare the performance of the two approaches, direct field measurements by inventory teams and TLS measurements, to determine the four individual-tree structural parameters total tree height, stem diameter at ground height, length of the longest branch and height of the longest branch.

Specifically, we tested three hypotheses in this study:

(H1) TLS-derived data are highly congruent with field measurement data.

(H2) Congruence of data varies with the observed structural parameter, decreasing in the order: total height $>$ stem diameter $>$ length the longest branch $>$ height of the longest branch.

(H3) Variance of direct field and TLS measurement data can mainly be explained by extrinsic factors (e.g. potential occlusion, point cloud quality).

\section{Material and methods}

\subsection{Study site}

The study site is located in a hilly subtropical region near Xingangshan Township, Jiangxi Province (29.08-29.11 N, 
117.90-117.93 E), China. The mean annual temperature is $16.7{ }^{\circ} \mathrm{C}$ and the mean annual precipitation $1,821 \mathrm{~mm}$. The potential natural vegetation of this region is subtropical broadleaved forest with evergreen species dominating in abundance (Bruelheide et al. 2011). Each of the 556 plots in the BEFChina experiment has a projected area of $666.7 \mathrm{~m}^{2}(25.8 \times$ $25.8 \mathrm{~m})$ and was planted with 400 tree saplings $(20 \times 20)$ in 2009 and 2010, resulting in a total of 219,200 trees (detailed descriptions of the experimental design are given by Yang et al. 2013; Bruelheide et al. 2014). The horizontal planting space is $1.29 \mathrm{~m}$, resulting in a stem density of 6,000 trees ha $^{-1}$. The plot tree species richness levels are 1, 2, 4, 8, 16, and 24 . To maintain the designed plot compositions, herbaceous and non-planted woody species are mechanically removed from all plots in weeding campaigns conducted twice a year.

Due to the large number of trees planted in the experiment, the direct annual measurements are focused on trees within the central part of every plot. In monocultures and 2-species mixtures the central $6 \times 6$ planting positions (i.e., 36 trees per plot), and in the 4-, 8-, 16- and 24-species mixtures the central $12 \times 12$ planting positions (i.e., 144 trees per plot) are sampled. For TLS, 14 plots were selected according to the following criteria: (1) monoculture or 2-species mixture; (2) high proportion of trees larger than $1 \mathrm{~m}$ high; (3) high proportion of living trees in the planting positions; (4) only deciduous broad-leaved tree species or at least one out of two tree species deciduous. A total of nine tree species were recorded from the 14 plots: Choerospondias axillaris (Roxburgh) Burtt et Hill, Diospyros japonica Siebold et Zuccarini, Liquidambar formosana Hance, Nyssa sinensis Oliver, Sapindus saponaria Linnaeus, Triadica cochinchinensis Loureiro, Triadica sebifera (L.) Small, Schima superba Gardner and Champion, Rhus chinensis Miller. All the recorded tree species are deciduous broad-leaved, with the exception of $S$. superba, which is an evergreen broad-leaved species.

\subsection{Data collection}

\subsubsection{Direct field measurement}

The direct annual field measurements were conducted at the end of the growing season from the middle of September until the end of October. Trees were surveyed under leaf-on conditions for the deciduous trees in order to measure the crown dimensions. The whole inventory was conducted by ten trained teams consisting of two persons each (hereafter inventory teams). In this study, we use the inventory data of the selected 14 plots that were recorded by seven inventory teams in September/October 2011. Each tree in the experiment is tagged with a unique numeric code. For every living tree in the total of 504 planting positions, the total tree height and the stem diameter at $5 \mathrm{~cm}$ above ground (hereafter ground diameter (GD)) were determined. GD was measured instead of diameter at breast height (DBH) because of the young age of the trees. Total height was measured as the length from the stem base to the apical meristem with a measuring pole. GD was measured with a caliper to the nearest millimeter without prescribed measuring direction, and the position of the diameter measurement was permanently marked on the stem with white paint. We also measured the length and the height of the longest branch with a measuring tape and counted the number of living first-order branches ( $>1 \mathrm{~cm}$ in length) of every tree. The length of the longest branch was measured as the straight distance between the branch collar and the branch apical meristem. A summary of tree structural parameters is presented in Table 1.

\subsubsection{TLS data acquisition}

In the selected 14 plots, TLS was conducted in March 2012 under leaf-off conditions of the deciduous trees. The scans were performed with a phase-shift FARO Laser Scanner Photon 120 (FARO Technologies, Inc., FL, USA). The vertical field-of-view of each panorama scan is $310^{\circ}$ and the horizontal is $360^{\circ}$. The scanner resolution was set at $1 / 4$, corresponding to an angular resolution of $0.036^{\circ}$ and a spatial resolution of $6.283 \mathrm{~mm}$ at a distance of $10 \mathrm{~m}$ from the device. The data acquisition rate was 244,000 points per second. Further details on technical specifications and the experimental settings are presented in Table 2. One scan with the aforementioned configuration took about 3:24 $\mathrm{min}$. The laser scanner was positioned on a tripod at a height of about $1.3 \mathrm{~m}$. Due to the intrinsic characteristics of the laser device and the geometric measurement pattern, the 3D point density varied along the distance from scanner to object, and spatial information on the surface of vegetative elements located behind another object is not available due to occlusion (for more details see van der Zande et al. 2006). In order to obtain a complete 3D picture of all focal trees in each plot, several scans from different angles are required (Watt and Donoghue 2005). Due to the schematic planting pattern of the trees, we were able to make use of a standardized set-up of scan positions comprising nine scans evenly positioned on the plot (Fig. 1). To co-register the point clouds from the nine scans (see below), artificial and highly reflective reference targets

Table 1 Summary of tree structural parameters obtained from direct field measurements on 14 plots (number of trees $=438$ )

\begin{tabular}{lll}
\hline & Range (min.-max.) & Mean \pm SD \\
\hline Total tree height $(\mathrm{cm})$ & $23-540$ & $238.4 \pm 112.6$ \\
Ground diameter $(\mathrm{cm})$ & $0.4-9.5$ & $3.5 \pm 1.6$ \\
Length of the longest branch $(\mathrm{cm})$ & $3-484$ & $131.2 \pm 88.6$ \\
Height of the longest branch $(\mathrm{cm})$ & $0-340$ & $75.2 \pm 59.8$ \\
Number of branches & $0-59$ & $13 \pm 11$ \\
\hline
\end{tabular}


Table 2 Technical specifications and experimental settings of the FARO LS Photon 120

\begin{tabular}{lll}
\hline FARO LS Photon 120 & Hardware specifications & Experimental settings \\
\hline Laser power & $20 \mathrm{~mW}$ (Laser class 3R) & - \\
Wavelength & $785 \mathrm{~nm}$ & - \\
Range finder/method & Phase-shift & - \\
Measurement range & $0.6-120 \mathrm{~m}$ & - \\
Ranging error & $\pm 2 \mathrm{~mm}($ at $25 \mathrm{~m})$ & $310^{\circ} \times 360^{\circ}$ \\
Field-of-view $(\mathrm{V} \times \mathrm{H})$ & Up to $310^{\circ} \times 360^{\circ}$ & $0.036^{\circ}$ \\
Angular step size $(\mathrm{V}, \mathrm{H})$ & Up to $0.009^{\circ}$ & $6.283 \mathrm{~mm}(\mathrm{at} 10 \mathrm{~m})$ \\
Spatial resolution & Up to $2 \mathrm{~mm}($ at $15 \mathrm{~m})$ & 244,000 points $/ \mathrm{s}$ \\
Data acquisition rate & Up to 976,000 points $/ \mathrm{s}$ &
\end{tabular}

(ten polystyrene spheres, each with a radius of $7 \mathrm{~cm}$ and three sheet metal checkerboards each with $42 \times 46 \mathrm{~cm}$ edge lengths) were placed within and around the sampling area (Fig. 1).

The TLS was conducted in March in order to minimize adverse impacts from high air humidity and wind as well as to avoid the occlusion from deciduous tree foliage and from high understory vegetation. During that time, air humidity is relatively low, and the scans were performed under windless conditions or at very low wind velocity. The time lag between the direct field measurements and TLS could introduce a systematic bias. Because the deciduous trees were in winter dormancy and the evergreen trees only show a very small increment between October and April (unpublished data), we assume that deviations caused by the time lag are largely restricted to a few trees where branch or stem breakage might have occurred during winter.

\subsubsection{TLS data processing and extraction}

The co-registration of the point clouds from nine scans within each plot was carried out with FARO Scene (V. 5.0.1) in order to yield a complete 3D representation for each plot (Fig. 2a). The artificial reference targets were automatically identified by FARO Scene to enable positioning of each individual scan. Each point of the $3 \mathrm{D}$ picture is characterized by an $X Y Z$ coordinate. To enhance the point cloud quality of focal trees, outliers and points with low reflection intensity were removed by a set of predefined standard filters. As a process of segmentation, we used the software Pointools Edit (V. 1.5) to isolate the focal trees manually from all laser pulse returns that were extraneous to the focal trees (i.e. surrounding vegetation and soil) (Fig. 2b). Independently of data measured directly in the field, TLS measurements of total tree height, GD as well as length and height of the longest branch were made manually with Pointools Edit. The built-in navigation allowed an easy and quick visual identification of the focal trees and relatively quick measurements of the tree parameters. Total height was determined by averaging two measurements of the lengths from the point representing stem base to the endpoint of the highest crown. For GD measurement (Fig. 3), the stem crosssection was taken manually at the position marked with white paint, or $5 \mathrm{~cm}$ above ground if the mark was absent or not
Fig. 1 Plot layout and standardized set-up of nine scan positions to acquire terrestrial laser scanning (TLS) data. The north sphere allowed for orientation to the cardinal directions. The set-up scheme of the spheres within the plot had no fixed pattern, but was adjusted depending on vegetation density and topography. The horizontal distance between two planting positions is $1.29 \mathrm{~m}$, resulting in a horizontal plot size of $41.6 \mathrm{~m}^{2}$

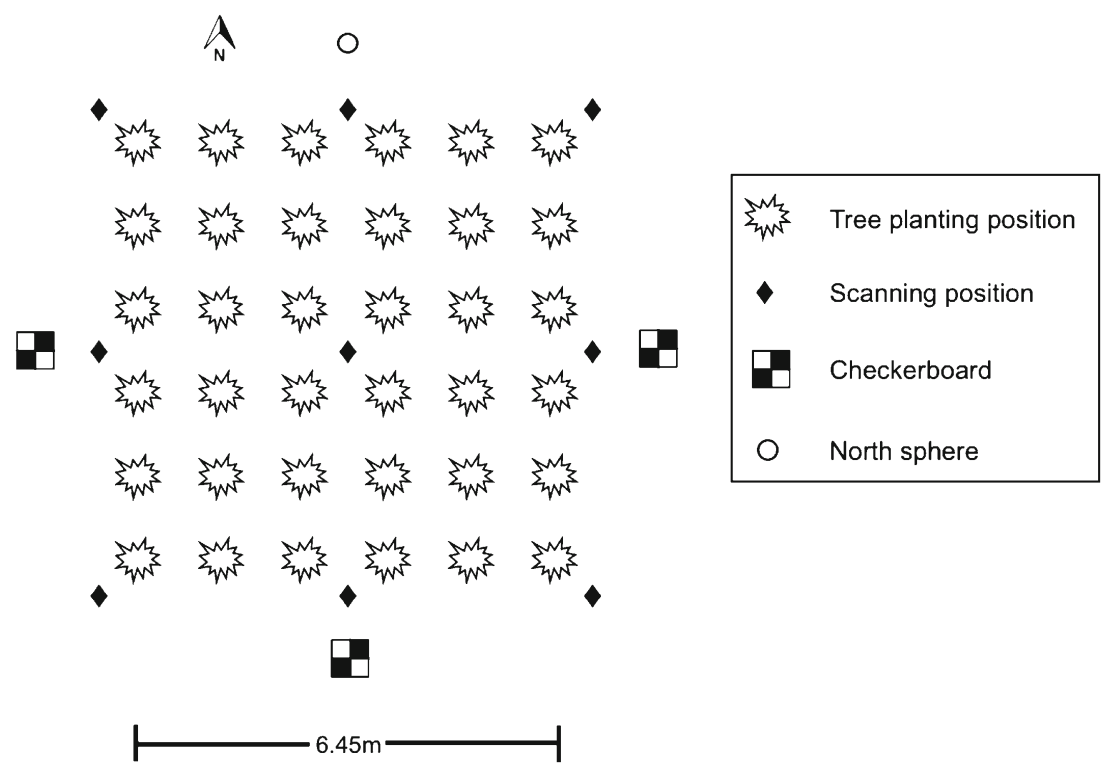


a) 3D point cloud scene of one plot

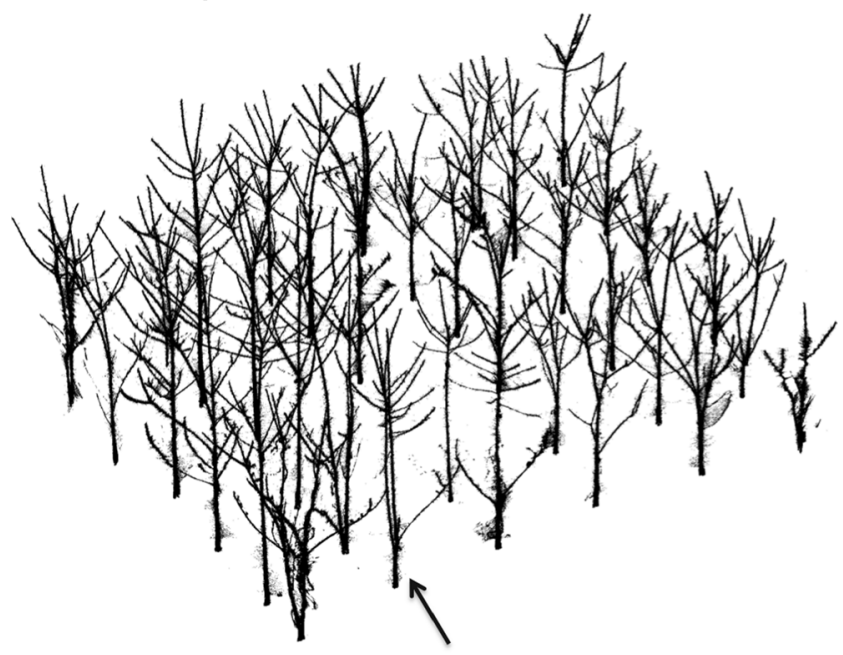

b) 3D point cloud scene of an isolated tree

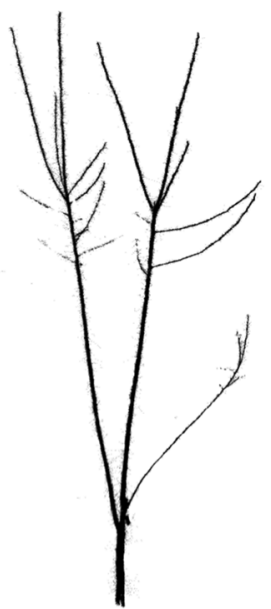

Fig. 2 Three-dimensional (3D) point cloud scene of one plot and an isolated tree

detected due to occlusion. The maximum diameter and its orthogonal were visually determined and manually measured with the tool "distance measure". GD was calculated as the average of these two measurements. Additionally, to examine whether the congruence of GD measurements varies according to the point cloud quality of the cross-sections, we introduced three quality classes, namely class 0 , class 1 , and class 2. Cross-sections with incomplete contours were classified as class 0 ; those with a complete contour but without white paint mark were categorized as class 1 ; those with both complete contour and white paint mark were grouped into class 2 . The longest branch was first identified from different view angles. The length of the detected longest branch was measured as the length between the branch collar and the endpoint of the branch. The length between the stem base and the branch collar was measured as the height of the longest branch.

An overview of the numbers of measured individual trees per tree structural parameter for direct field and point cloud measurement is presented in Table 3 .

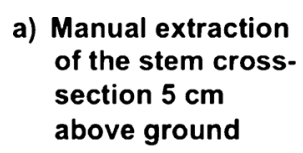

b) Measurement using Pointools tool "distance measure" of the maximum diameter and its orthogonal of the stem crosssection

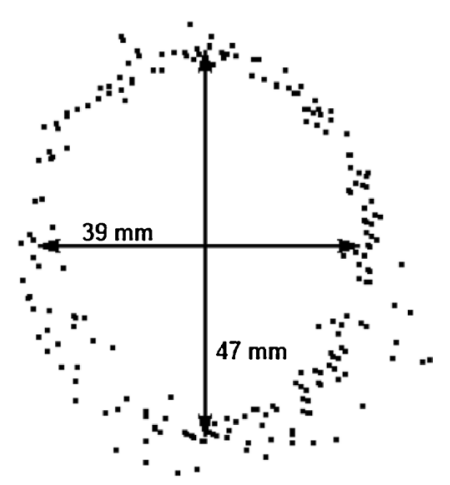

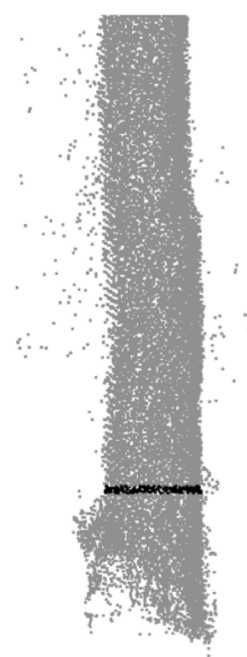

Fig. 3 Manual extraction of the stem cross-section $5 \mathrm{~cm}$ above ground, and visual determination and manual measurement using the Pointools tool "distance measure" of the maximum diameter and its orthogonal of the stem cross-section

\subsection{Data analysis}

We used correlation analyses to compare TLS-retrieved data with the field-measured data. Pearson correlations were applied for normally distributed data (total tree height and GD), whereas Spearman rank correlations were used for nonnormally distributed data (length and height of the longest branch). Root-mean-square error (RMSE) was calculated to obtain the standard deviation of TLS-retrieved data from field measured data. We implemented generalized linear models (GLM) with binomial family to test whether the proportional deviation of the TLS data from inventory data was dependent on extrinsic factors, including potential occlusion (sum of GDs of the focal tree's nearest neighbors, sum of all GDs on plot level), inventory team, point cloud quality of GDs, the structural parameters of the focal trees (total height and

Table 3 Number of measured tree individuals per tree structural parameter for the direct field measurements and terrestrial laser scanning (TLS) measurements

\begin{tabular}{|c|c|c|}
\hline & \multicolumn{2}{|c|}{ Number of measured tree individuals } \\
\hline & $\begin{array}{l}\text { Direct field } \\
\text { measurement }\end{array}$ & $\begin{array}{l}\text { TLS } \\
\text { measurement }\end{array}$ \\
\hline Total tree height & 438 & 431 \\
\hline Ground diameter & 438 & 391 \\
\hline Length of the longest branch & 431 & 408 \\
\hline Height of the longest branch & 431 & 408 \\
\hline
\end{tabular}


number of branches), as well as species identity. All factors were scaled in order to make the model estimates comparable. GD data was transformed by multiplying it by 10 . Data for length and height of the longest branch were square-roottransformed. Each tree structural parameter was tested against each selected factor except GD point cloud quality. Only GD was tested against the point cloud quality. For GLM with a categorical predictor, an ANOVA (using type "III" to cope for the unbalanced level proportions) was applied to test whether the variance was significantly different among the levels of one factor. Statistical analyses were conducted in R 3.0.1 (R Development Core Team). Package hydroGOF was used for calculating RMSE. The deviance percentage obtained from the chi-square test was calculated using package BiodiversityR for the proportion of the explained variance by one specific factor. Package car was used for analyzing the type "III" ANOVA.

\section{Results}

According to the direct field measurements, 438 living trees were present in the total of 504 surveyed planting positions. Of these, seven trees were branchless (Table 3). TLS data successfully detected 431 trees. For all of these trees, the total height was measured in the point clouds, GD measurements were conducted for 391 trees, and the length and the height of the longest branch was determined for 408 trees (Table 3).

The correlation coefficients between direct field and TLS measurements for total tree height, GD and length of the longest branch were very high $\left(r \geq 0.95^{* * *}\right)$, whereas that for the height of the longest branch was fairly high $\left(r=0.81^{* * *}\right.$; Fig. 4). In height measurements, a higher proportion of comparisons showed larger values in the direct field measurements than in the TLS measurements (points below the equality line in Fig. 4a), but the absolute divergence was almost always small. Most of the outliers, however, occurred above the equality line and concerned larger tree heights $(>250 \mathrm{~cm})$. In GD measurements, points were equally distributed above and below the equality line (Fig. 4b). A somewhat larger divergence between the measurement results was seen mostly for smaller values in the direct field than in TLS measurements (points above the equality line in Fig. 4b). The comparison of the measurements of the length of the longest branch revealed a larger number of points below the equality line, but outliers were exclusively observed above the line (i.e., value direct field measurement $<$ TLS measurement; Fig. $4 \mathrm{c}$ ). The distribution of the points for the height of the longest branch was relatively scattered, with several extreme outliers below the line (Fig. 4d).

As Table 4 shows, the variance of direct field and TLS measurements for total tree height was influenced slightly by the sum of the GD on both the local neighborhood level (estimate $=0.01)$ and the plot level (estimate $=0.02)$. Furthermore, the variance differed significantly between inventory teams and tree species. The variance of GD measurements was only significantly related to the focal tree's height (estimate $=0.03$ ), however, with an overall low explained variance $(r=3.13 \%)$. None of the factors included in the GLM contributed to the explanation of the two measurement approaches regarding the two tree structural parameters length and height of the longest branch.

\section{Discussion}

In the selected 14 plots, the survival rate of planted trees was $87 \%$, which corresponds exactly to the overall survival rate of planted trees in the entire BEF-China experiment during the census interval April 2009 to June 2010 (Yang et al. 2013). The TLS data successfully detected more than $98 \%$ of the living trees. All seven trees that were not found in the point clouds were small, with a total height below $40 \mathrm{~cm}$ and a GD below $0.8 \mathrm{~cm}$. Although the experimental plots were regularly weeded, and although most of the herbaceous vegetation retreats during the winter months, a tree height of $40 \mathrm{~cm}$ seems to be the minimum size that is required for tree detection and height measurements with the TLS set-up used in this study. For about $10 \%$ of the TLS-detected trees, the GD could not be determined from TLS data. This was mainly due to occlusion of the stems caused by ground layer vegetation as well as other planted trees that were positioned between the laser scanner and the focal tree. Furthermore, in the only evergreen tree species, S. superba, leaved branches often reached down to low heights and occluded the stem at ground height. As a result, fragments with less than half of the cross-section contour appeared at ground height, and these trees were excluded from GD measurements. In a few cases, numerous fuzzy points occurred in the cross-section preventing a clear delineation of the stem surface. However, this was restricted to the smallest trees that were surrounded by herbaceous vegetation. Finally, in 19 trees, it was not possible to identify the longest branch. Most of these trees were $S$. superba, reinforcing the advantages of leaf-off compared to leaf-on conditions for enhancing the level of accuracy in detailed TLS measurements (Henning and Radtke 2006; Maas et al. 2008).

As expected (H1), TLS-derived data were highly congruent with data from direct field measurements. Generally, conventional measurements of height are more prone to measuring inaccuracies than those of the stem diameter (Pretzsch 2009). In our study, however, tree height data obtained by TLS approximated field-collected data even more closely than GD data. We suppose that the main reason is that the total height of the trees measured in this study still allowed for accurate direct height measurements with a measuring pole, whereas heights of larger trees $(>6 \mathrm{~m})$ have to be obtained by 
Fig. 4 Comparison between direct field measurement and terrestrial laser scanning (TLS) measurements for a total tree height, $\mathbf{b}$ stem diameter at ground height (ground diameter), c length of the longest branch, and d height of the longest branch. The correlation coefficient $(r)$ and the root-mean-square-root error (RMSE) of the two measurements are 0.98 and $20.56 \mathrm{~cm}$ for total tree height, 0.95 and $0.52 \mathrm{~cm}$ for $\mathrm{GD}, 0.95$ and $34.25 \mathrm{~cm}$ for length of the longest branch, and 0.81 and $38.12 \mathrm{~cm}$ for height of the longest branch, respectively. All correlations are truly correlated and significantly not equal to 0 $(\operatorname{Pr}<0.001)$ a) Total tree height $(\mathrm{cm})$

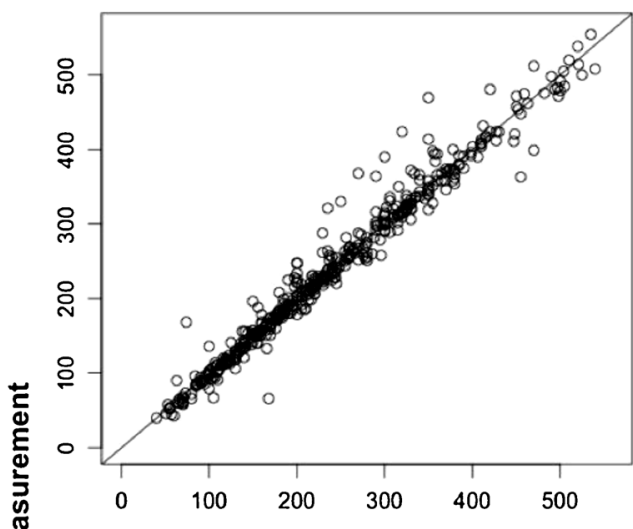

c) Length of the longest branch (cm)

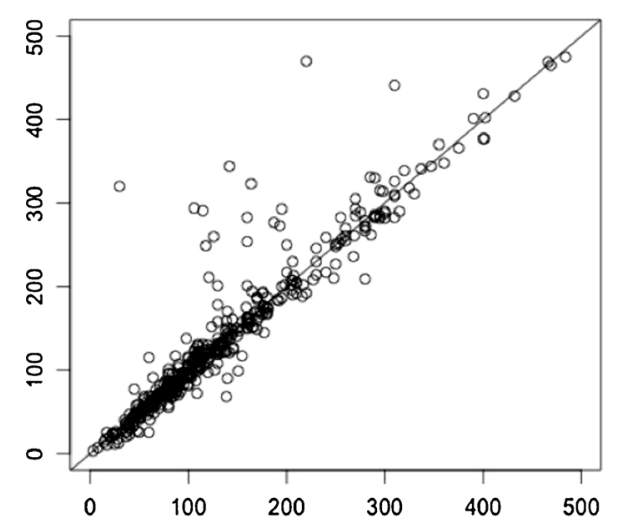

b) Ground diameter $(\mathrm{cm})$

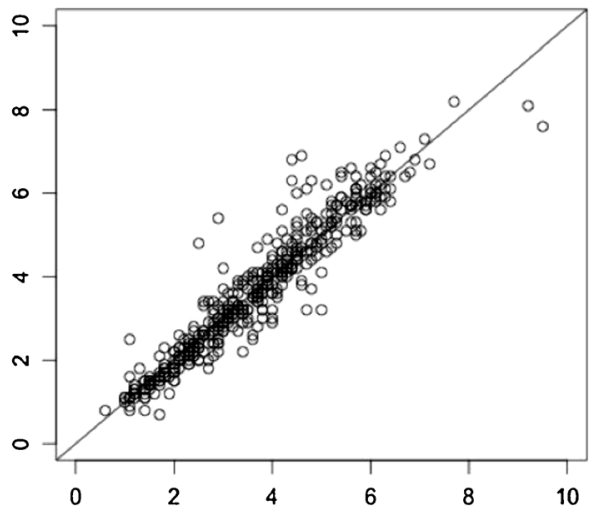

d) Height of the longest branch (cm)

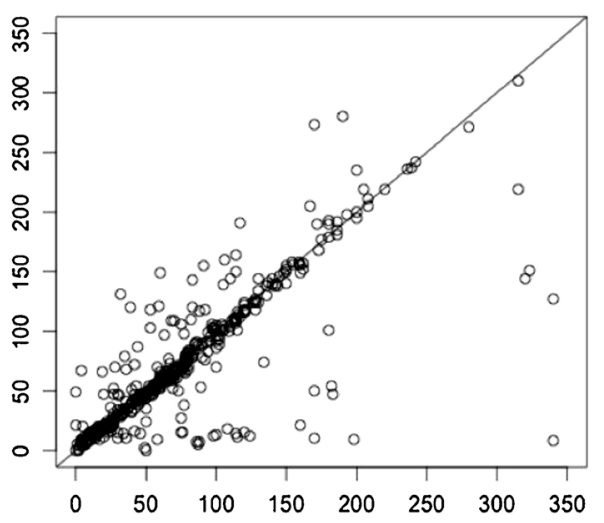

Direct field measurement

optical or laser tools such as a hypsometer. For time reasons, only one stem diameter measurement with a caliper was done in the field, which may cause inaccuracies in the case of noncircular stem cross-sections (see below).
On average, TLS tended to slightly underestimate total tree height and length of the longest branch. One reason for this might be that the direct field measurements were carried out under leaf-on conditions, whereas TLS was done under leaf-

Table 4 Results of generalized linear models (GLM) for the comparison of data on four tree structural parameters derived from direct field measurements and terrestrial laser scanning (TLS) measurements (given as estimates, i.e., the percentage of the variance explained)

\begin{tabular}{|c|c|c|c|c|c|}
\hline & & \multicolumn{4}{|c|}{ Tree structural parameter } \\
\hline & & $\mathrm{H}$ & GD & Llong & Hlong \\
\hline \multirow[t]{7}{*}{ Estimate (the explained variance) } & GDN & $0.01 * *(1.9 \%)$ & n.s. & n.s. & n.s. \\
\hline & GDP & $0.02 * * *(4.3 \%)$ & n.s. & n.s. & n.s. \\
\hline & IT & n.d. $* * *(16.8 \%)$ & n.s. & n.s. & n.s. \\
\hline & PCQ & n.d. & n.s. & n.d. & n.d. \\
\hline & $\mathrm{H}$ & n.s. & $0.03 *(3.13 \%)$ & n.s. & n.s. \\
\hline & NB & n.s. & n.s. & n.s. & n.s. \\
\hline & Species & n.d. $* * *(7.2 \%)$ & n.s. & n.s. & n.s. \\
\hline
\end{tabular}

Tree structural parameters: $H$ total tree height, GDstem diameter at ground height, Llong length of the longest branch, Hlong height of the longest branch, the continuous predictors include $G D N$ sum of the focal tree's neighboring GDs, GDP sum of all GDs within a plot, $H$ total tree height of the focal tree, $N B$ the number of branches of the focal tree, the categorical predictors include IT inventory team, $P C Q$ GD point cloud quality, Species species identity, n.s. statistically not significant, $n . d$. not determined

$* * * \operatorname{Pr}<0.001 ; * * 0.001 \leq \operatorname{Pr}<0.01 ; * 0.01 \leq \operatorname{Pr}<0.05$ 
off conditions for the deciduous trees. Some of the tree species have long leaves ( 15 to $40 \mathrm{~cm}$ ), and some of the direct height or length measurements in autumn might have been erroneously carried out up to the highest leaf tip instead of to the highest apical meristem (cf. Wezyk et al. 2007). Furthermore, the spatial position of the tips of the highest branch in the tree crown and of the longest branch may differ under leaf-on and leaf-off conditions. In addition, these tips belong to the smallest tree constituents. They may be most sensitive to movements due to wind. They likely have a relatively low number of data points or could be occluded by other branches (Fig. 5; Côté et al. 2012; Schilling et al. 2012). Finally, the lowest point of each isolated focal tree was assumed to represent the stem base. However, the stem base could have been occluded by other objects (Fig. 5), resulting in a starting point for the TLS height measurements that was positioned above the stem base. Most of the outliers, however, indicated that TLS overestimated the height of trees which were larger than $250 \mathrm{~cm}$. We suppose that this is mainly due to errors in the direct height measurements in the field: In some situations, the identification of the highest point of a tree could have been difficult due to a very dense canopy, meaning that a lower point was measured. In the length measurements, all outliers also showed a TLS-overestimated pattern. In these (few) cases, we assume that the tree individuals were treated differently in the two measurements: the object that was identified as the longest branch in TLS measurement was considered to be a second stem in the direct field measurement. Despite

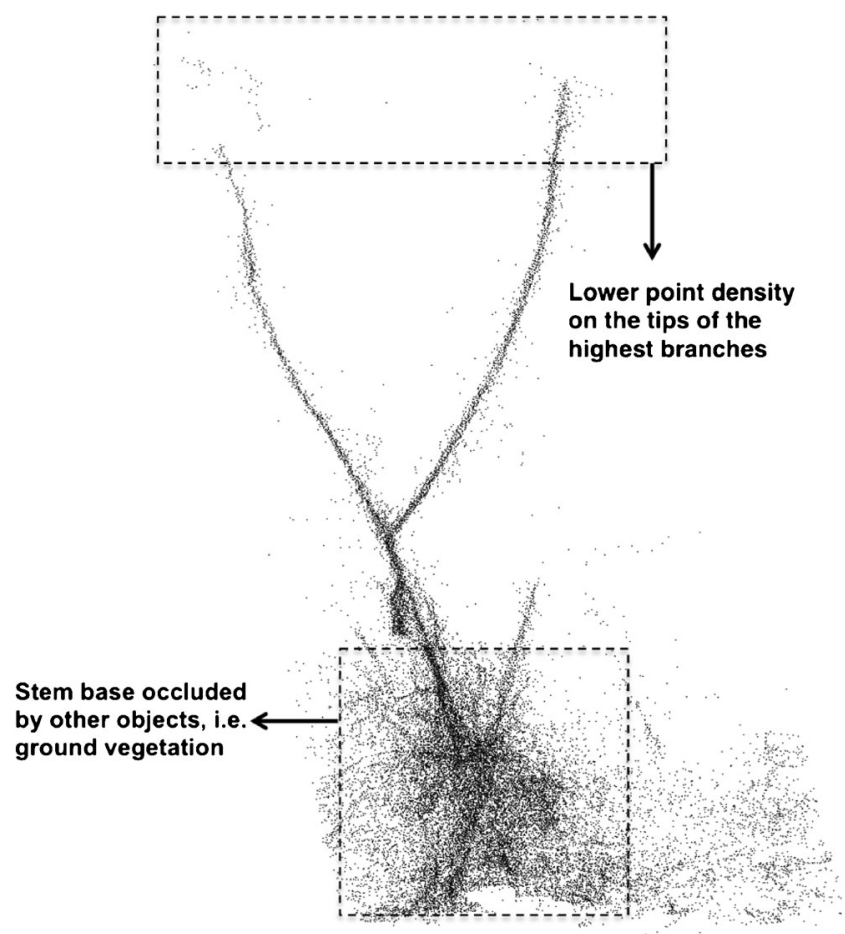

Fig. 5 Lower point density on the tips of the highest branches and tree stem base severely occluded by ground vegetation these potential sources of under- or overestimation in TLSderived total height and length of the longest branch, the agreement between the two approaches was generally very good, and the differences observed were mostly in the order of $25 \mathrm{~cm}$ or less.

The TLS stem diameter measurements have often been found to be underestimations compared to the direct measurements (Watt et al. 2003; Thies and Spieker 2004; Weiß 2009), but this was not confirmed in our study. The underestimation is due to the curvature of the stem surface, producing inaccurate distance and intensity measurements at the outer parts of the stem. However, this is much less relevant in multiple scan data than in single scan data. According to Pueschel et al. (2013), the full coverage of a tree stem's circumference is crucial for the reliable determination of stem diameters. With the exceptions mentioned above, this was successfully achieved in our TLS data set. Another source of variation between the two approaches results from the non-circularity of the stem cross-section (Pueschel et al. 2013). The deviation of the stem girth from a circle may generally be higher at ground height than at breast height. We, therefore, assume that much of the variation observed for the GD measurements is due to measurement procedure: in the field, only one diameter was determined with a caliper, whereas the maximum and minimum diameter was averaged in the TLS data set. In noncircular stem cross-sections this may result in over- or underestimations. As soon as possible, the DBH was, or will be, measured in the field inventory and accordingly in the TLS data. For two reasons in particular, we expect that the congruence between the two approaches will be even higher in the DBH than in the GD measurements: no occlusion from the ground layer vegetation and less deviation of the stem girth from a circle at breast height than at ground height.

The most notable differences were observed for the height determination of the longest branch. Here, we suggest that the $3 \mathrm{D}$ environment of the point clouds and the convenient navigation in Pointools allows for a more accurate identification of the longest branch than is possible in the field. Since this measurement is most sensitive to the identification procedure, it is conceivable that the level of congruence between the two approaches is lowest for this tree structural parameter (see H2).

Contrary to our third hypothesis, our results showed that the potential obstruction by other trees, employment of different inventory teams, as well as size and species identity of the focal tree contributed only slightly or not at all to the explanation of the variance between direct field and TLS measurements. Only tree height measurements varied due to the inventory team: in the field inventory, both team members were involved in the measurement procedure for trees $>2.5 \mathrm{~m}$ height, enhancing the likelihood of measuring inaccuracies. A higher sum of GD of the neighboring trees can be due to a higher density and/or larger stem size. Stand density is 
generally considered to have a key influence on the quality of the information from TLS (Watt and Donoghue 2005; Van der Zande et al. 2006). The density of more than 5,000 trees ha ${ }^{-1}$ in our plots can be regarded as relatively high for application of TLS (Watt and Donoghue 2005). However, the low effect size (tree height) and non-significant influence (other three tree structural parameters), respectively, of the GD sum of neighboring trees implies that the scanning set-up scheme applied in our study was adequate to minimize the occlusion of focal trees. Furthermore, species identity was a significant predictor explaining the variance in height measurements, though with a small effect size. The saplings of the tree species of these subtropical broad-leaved forests differ considerably in growth rates and tree architecture (Geißler et al. 2012; Lang et al. 2012). To determine the highest point of the tree crown in the field inventory might be easier in trees with a light and simple structure crown, such as $S$. saponaria. Finally, a small proportion of the variance in the GD measurements could be explained by focal tree height. In our study, trees of greater height were predominantly $C$. axillaris. Tree individuals of this species were often multi-stemmed, leading to noncircularity of the stem cross-section at ground height, which may explain the higher deviation of the two measurement approaches with increasing tree height. However, most of the variance between direct field and TLS measurements could not be explained by the factors considered in the GLM analyses, but might be due to the factors mentioned above (i.e., small dimension of some important tree constituents, occlusion by ground layer vegetation, wind-induced movements, identification procedure).

Due to the current lack of reliable automated approaches in tree segmentation and measurements, the data retrieval of the four tree parameters from TLS is more time-consuming than by direct field measurement in small trees (per tree about $12 \mathrm{~min}$ from TLS and about $5 \mathrm{~min}$ in the field). However, as soon as the trees grow larger, the non-destructive quantification of crown parameters becomes more time-consuming or even impossible with a high degree of accuracy. However, the TLS alternative not only saves time when conducting certain measurements in larger trees, but also provides several other benefits: it is a documentation tool with the full option for future analyses, including precise time series analyses; it allows the estimation of individual-tree wood volume, both for the whole tree and various constituents (stem and branches; Dassot et al. 2012); it enables the analysis of the 3D structural topology of trees as well as the 3D distribution of plant material (Seidel et al. 2011b); and it provides the basis for tree crown modeling which can be used to investigate light harvesting and tree-tree-interactions (Seidel et al. 2011c; Metz et al. 2013). In recent years, several methods for reconstructing trees or parts of trees in 3D have been developed (Eysn et al. 2013). Automatic methods for tree modeling include voxel-based and geometric models. These approaches are, however, sensitive to point cloud quality and varying point density, and therefore manual or semi-automatic processing is still an option to enhance the quality of results (Dassot et al. 2012; Eysn et al. 2013).

We conclude that TLS enables a reliable determination of tree structural parameters in young trees under field conditions. The scanning set-up scheme used in this study produced point clouds of high quality, enabling us to detect all trees higher than $40 \mathrm{~cm}$ and to reduce occlusions (Fig. 2). Furthermore, TLS data analyses proved to be more accurate in the identification of certain structural features than the direct field inventory and can help to reduce the measuring inaccuracies caused by the employment of several different inventory teams in the field. However, two factors may restrict the application of TLS to young regenerating stands: the structural complexity of these stands and the current lack of automated tools for data extraction. The regular weeding of the experimental plots was strongly beneficial to the accuracy of TLS measurements, and stands with an even higher tree density and/or herbaceous vegetation will require adjusted scan settings. In extreme cases, however, TLS will only be possible after canopy closure and self-thinning. In relatively small evergreen trees with dense crowns, the woody structures are largely occluded by leaves; however, tree growth with natural pruning of the lower branches will increase the visibility of structural elements of the crown when using ground-based TLS. Further research is needed to achieve more rapid point cloud data processing by the development of automated methods.

Acknowledgments This research was carried out as part of the BEFChina project financed by the German Research Foundation (DFG FOR 891/2). We are grateful to all members of BEF-China for their support and to Lars Goldbach for his valuable assistance in the scanning campaign. We thank the two anonymous reviewers for comments that considerably improved the earlier version of the manuscript.

\section{References}

Brisson J (2001) Neighborhood competition and crown asymmetry in Acer saccharum. Can J For Res 31:2151-2159

Bruelheide H, Böhnke M, Both S, Fang T, Assmann T, Baruffol M, Bauhus J, Buscot F, Chen XY, Ding BY, Durka W, Erfmeier A, Fischer M, Geißler C, Guo DL, Guo LD, Härdtle W, He JS, Hector A, Kröber W, Kühn P, Lang AC, Nadrowski K, Pei KQ, SchererLorenzen M, Shi XZ, Scholten T, Schuldt A, Trogisch S, von Oheimb G, Welk E, Wirth C, Wu YT, Yang XF, Zeng XQ, Zhang SR, Zhou HZ, Ma KP, Schmid B (2011) Community assembly during secondary forest succession in a Chinese subtropical forest. Ecol Monogr 81:25-41

Bruelheide H, Nadrowski K, Assmann T, Bauhus J, Both S, Buscot F, Chen XY, Ding BY, Durka W, Erfmeier A, Gutknecht J, Guo D, Guo LD, Härdtle W, He JS, Klein A, Kühn P, Liang Y, Liu X, Michalski S, Niklaus P, Pei K, Scherer-Lorenzen M, Scholten T, Schuldt A, Seidler G, von Oheimb G, Welk E, Wirth C, Wubet T, Yang XF, Yu MJ, Zhang SR, Zhou HZ, Fischer M, Ma KP, Schmid B (2014) Designing forest biodiversity experiments: general considerations 
illustrated by a new large experiment in subtropical China. Methods Ecol Evol. doi: 10.1111/2041-210X.12126

Bucksch A, Lindenbergh R, Menenti M (2010) SkelTre - robust skeleton extraction from imperfect point clouds. Vis Comput 26:1283-1300

Côté JF, Fournier RA, Egli R (2011) An architectural model of trees to estimate forest structural attributes using terrestrial LiDAR. Environ Model Software 26:761-777

Côté JF, Fournier RA, Frazer GW, Niemann KO (2012) A fine-scale architectural model of trees to enhance LiDAR-derived measurements of forest canopy structure. Agric For Meteorol 166-167: $72-85$

Dassot M, Constant T, Fournier M (2011) The use of terrestrial LiDAR technology in forest science: application fields, benefits and challenges. Ann For Sci 68:959-974

Dassot M, Colin A, Santenoise P, Fournier M, Constant T (2012) Terrestrial laser scanning for measuring the solid wood volume, including branches, of adult standing trees in the forest environment. Comput Electron Agric 89:86-93

Eysn L, Pfeifer N, Ressl C, Hollaus M, Grafl A, Morsdorf F (2013) A practical approach for extracting tree models in forest environments based on equirectangular projections of terrestrial laser scans. Remote Sens 5:5424-5448

Fleck S, Mölder I, Jacob M, Gebauer T, Jungkunst HF, Leuschner C (2011) Comparison of conventional eight-point crown projections with LiDAR-based virtual crown projections in a temperate oldgrowth forest. Ann For Sci 68:1173-1185

Geißler G, Lang AC, von Oheimb G, Härdtle W, Baruffol M, Scholten T (2012) Impact of tree saplings on the kinetic energy of rainfall - the importance of stand density, species identity and tree architecture in subtropical forests in China. Agric For Meteorol 156:31-40

Grams TEE, Anderson CP (2007) Competition for resources in trees: physiological versus morphological plasticity. Progr Bot 68: 356-381

Henning JG, Radtke PJ (2006) Detailed stem measurements of standing trees from ground-based scanning LiDAR. For Sci 52:67-80

Hilker T, van Leeuwen M, Coops NC, Wulder MA, Newnham GJ, Jupp DLB, Culvenor DS (2010) Comparing canopy metrics derived from terrestrial and airborne laser scanning in a Douglas-fir dominated forest stand. Trees-Struct Funct 24:819-832

Hopkinson C, Chasmer L, Young-Pow C, Treitz P (2004) Assessing forest metrics with a ground-based scanning lidar. Can J For Res 34:573-583

Jung SE, Kwak DA, Park T, Lee WK, Yoo SJ (2011) Estimating crown variables of individual trees using airborne and terrestrial laser scanners. Remote Sens 3:2346-2363

Kobe RK (2006) Sapling growth as a function of light and landscapelevel variation in soil water and foliar nitrogen in northern Michigan. Oecologia 147:119-133

Lang AC, Härdtle W, Baruffol M, Böhnke M, Bruelheide H, Schmid B, von Wehrden H, von Oheimb G (2012) Mechanisms promoting tree species coexistence: experimental evidence with saplings of subtropical forest ecosystems of China. J Veg Sci 23:837-846

Lichti DD, Gordon SJ, Stewart MP (2002) Ground-based laser scanners: operation, systems and applications. Geophys J Roy Astron Soc 56: 21-33

Maas HG, Bienert A, Scheller S, Keane E (2008) Automatic forest inventory parameter determination from terrestrial laser scanner data. Int J Remote Sens 29:1579-1593

Metz J, Seidel D, Schall P, Scheffer D, Schulze ED, Ammer C (2013) Crown modeling by terrestrial laser scanning as an approach to assess the effect of aboveground intra- and interspecific competition on tree growth. For Ecol Manage 310:275-288
Pretzsch H (2009) Forest dynamics, growth and yield: from measurement to model. Springer, Berlin

Pretzsch H, Seifert S, Huang P (2011) Beitrag des terrestrischen Laserscannings zur Erfassung der Struktur von Baumkronen. Schweiz Z Forstwes 162:186-194

Pueschel P, Newnham G, Rock G, Udelhoven T, Werner W, Hill J (2013) The influence of scan mode and circle fitting on tree stem detection, stem diameter and volume extraction from terrestrial laser scans. ISPRS J Photogramm Remote Sens 77:44-56

Schilling A, Schmidt A, Maas HG (2012) Tree topology representation from TLS point clouds using depth-first search in voxel space. Photogramm Eng Remote Sens 78:383-392

Seidel D, Beyer F, Hertel D, Fleck S, Leuschner C (2011a) 3D-laser scanning: a non-destructive method for studying above-ground biomass and growth of juvenile trees. Agric For Meteorol 151: 1305-1311

Seidel D, Fleck S, Leuschner C, Hammett T (2011b) Review of groundbased methods to measure the distribution of biomass in forest canopies. Ann For Sci 68:225-244

Seidel D, Leuschner C, Müller A, Krause B (2011c) Crown plasticity in mixed forests - quantifying asymmetry as a measure of competition using terrestrial laser scanning. For Ecol Manage 261:2123-2132

Stoll P, Schmid B (1998) Plant foraging and dynamic competition between branches of Pinus sylvestris in contrasting light environments. J Ecol 86:934-945

Sumida A, Terazawa I, Togashi A, Komiyama A (2002) Spatial arrangement of branches in relation to slope and neighborhood competition. Ann Bot 89:301-310

Thies M, Spieker H (2004) Evaluation and future prospects of terrestrial laser scanning for standardized forest inventories. Int Arch Photogram Rem Sens Spatial Inform Sci 36:192-197

Van der Zande D, Hoet W, Jonckheere I, van Aardt J, Coppin P (2006) Influence of measurement set-up of ground-based LiDAR for derivation of tree structure. Agric For Meteorol 141:147-160

Van Leeuwen M, Nieuwenhuis M (2010) Retrieval of forest structural parameters using LiDAR remote sensing. Eur J For Res 129: 749-770

Vehmas M, Packalén P, Maltamo M, Eerikäinen K (2011) Using airborne laser scanning data for detecting canopy gaps and their understory type in mature boreal forest. Ann For Sci 68:825-835

Watt PJ, Donoghue DNM (2005) Measuring forest structure with terrestrial laser scanning. Int J Remote Sens 26:1437-1446

Watt PJ, Donoghue DNM, Dunford RW (2003) Forest parameter extraction using terrestrial laser scanning. Proc. ScandLaser Scientific Workshop on Airborne Laser Scanning of Forests, Umeå, Sweden, 237-244

Weiß J (2009) Application and statistical analysis of terrestrial laser scanning and forest growth simulations to determine selected characteristics of Douglas-Fir stands. Folia For Pol, Ser A 51:123-137

Wezyk P, Koziol K, Glista M, Pierzchalski M (2007) Terrestrial laser scanning versus traditional forest inventory: First results from the Polish forests. In: Proc. Laser Scanning 2007 and Silvilaser 2007. ISPRS Commission III Workshop, Vol. 36, Part 3, Espoo, Finland, Sept. 12-14, 2007

Yang XF, Bauhus J, Both S, Fang T, Härdtle W, Kröber W, Ma KP, Nadrowski K, Pei KQ, Scherer-Lorenzen M, Scholten T, Seidler G, Schmid B, von Oheimb G, Bruelheide H (2013) Establishment success in a forest biodiversity and ecosystem functioning experiment in subtropical China (BEF-China). Eur J For Res 132:593-606

Zimble DA, Evans DL, Carlson GC, Parker RC, Grado SC, Gerard PD (2003) Characterizing vertical forest structure using small-footprint airborne LiDAR. Remote Sens Environ 87:171-182 